\title{
FUNDAMENTAL STUDIES OF
}

\section{HALOGEN REACTIONS WITH III-V SEMICONDUCTOR SURFACES}

\author{
William C. Simpson ${ }^{1}$ and Jory A. Yarmoff \\ Department of Physics, University of California, Riverside, California 92521, and \\ Materials Sciences Division, Lawrence Berkeley National Laboratory, Berkeley, \\ California 94720
}

KEY WORDS: semiconductor processing, gallium arsenide, chlorine, fluorine, etching

\begin{abstract}
It is technologically important to understand how halogens react with semiconductor surfaces because halogen compounds are commonly used to etch semiconductor wafers in the microelectronics industry. Halogens are also model adsorbates for studying chemisorption on covalently bonded materials, such as semiconductors, owing to the simple nature of the bonds that they form. The growing use of III-V materials in the manufacture of optoelectronic devices has prompted investigations of the reactions of molecular halogens $\left(\mathrm{XeF}_{2}, \mathrm{Cl}_{2}, \mathrm{Br}_{2}\right.$, and $\mathrm{I}_{2}$ ) with III-V semiconductor surfaces ( $\mathrm{GaAs}, \mathrm{GaSb}$, InP, InAs, and InSb). This review examines the more fundamental of these investigations, which involve model systems in ultra-high vacuum, focusing on the chemistry of the halogen surface reactions and the physical and electronic structure of the reacted surfaces.
\end{abstract}

\section{INTRODUCTION}

The field of surface science has matured sufficiently over the past 30 years that investigations of model systems are now giving way to studies of more complex real-life processes. One such real-life process that has received considerable attention in recent years is the etching of semiconductor surfaces, especially the etching of $\mathrm{Si}$ and GaAs by halogen compounds. Now, as a result of these investigations, much more is known about how halogens react

\footnotetext{
${ }^{1}$ Present address: Environmental Molecular Sciences Laboratory, Pacific Northwest National Laboratory, Richland, Washington 99352.
} 
with semiconductors and how these reactions alter the physical and electronic structure of the surfaces.

The fabrication of microelectronic devices relies on a class of techniques loosely categorized as dry processing. A subclass of dry processing is dry etching, in which a substrate is exposed to reactive gases, ion beams, or plasmas to etch a pattern into the surface by removing material. Since halogens form volatile species when reacted with most semiconductor materials, halogens and halogen-containing compounds are the most commonly used dry etchants. A serious drawback to dry etching, however, is that it often roughens a surface. Roughening introduces defects, both physical and electronic, which affect the performance of a microelectronic device. These defects are an increasing concern as the scale of modern-day devices shrinks to the submicron level. Thus, from a technological standpoint, an understanding of the fundamental mechanisms involved in the etching of semiconductor surfaces by halogens is essential.

Many practical aspects of III-V semiconductor etching have been studied in the past few years. In the fabrication of microelectronic devices, substrates are commonly etched by plasma discharges or by ions beams via reactive ion etching (RIE) or chemically assisted ion beam etching (CAIBE). Because of the technological importance of these processes, many studies (only some of which are listed here) have looked at how ion beams (1-31) and plasmas (32-37), as well as the individual constituents of plasmas [e.g. ions (1-31), atoms (38-41), radicals $(26,42-45)$, hot molecules $(46,47)$, electrons (48-55), and photons (56-69)], act to etch semiconductor substrates.

In a typical plasma environment, many chemical reactions and particlesurface interactions occur simultaneously. In order to model such a complex situation, each of the important surface chemical reactions must first be understood individually. Many fundamental studies have utilized such an approach, in which the important reactions are investigated using well-defined singlecrystal substrates in a highly regulated ultra-high vacuum (UHV) environment. Surfaces are cleaned, characterized, and exposed to controlled amounts of an etchant. As a first step, many studies investigate the chemisorption of reactant molecules on bare semiconductor surfaces in order to determine such things as adsorption kinetics and bonding geometries. These studies also serve to delineate the relevant spectroscopies. Once the initial chemisorption is understood, the various spectroscopic techniques are applied to surfaces exposed to sufficiently large quantities of reactants to promote spontaneous etching. The etching chemistry is then determined by either measuring the volatile reaction products directly or analyzing the reaction products that remain on the surface. Changes in the product distributions, in the surface morphology, and in the surface electronic structure are monitored as the exposure, temperature, crystal 
face, and substrate doping level are varied. A picture of the overall etching reaction is then developed by correlating measurements of both the volatile and nonvolatile reaction products.

This methodology has already been applied successfully to the etching of silicon substrates (70). Early investigations looked at the chemisorption of fluorine on clean Si surfaces (71), while subsequent work looked at more highly reacted surfaces $(72,73)$. Studies of the gaseous reaction products generated by the spontaneous etching of $\mathrm{Si}$ by fluorine also contributed greatly to the understanding of silicon-fluorine chemistry by complementing the investigations of the surface products $(74,75)$.

Recently, investigators have begun to study the etching of the more complex III-V semiconductors. The chemistry of these systems is complicated by the possibility of inhomogeneous etching and by the nature of the surfaces themselves: It is simply more difficult to produce clean, well-ordered surfaces of III-V materials than of $\mathrm{Si}$, which can lead to problems in the reproducibility of results. These more complex investigations comprise the material in this review.

Note that in addition to their industrial importance, halogens are an excellent class of adsorbates for studying chemisorption and are thus also interesting from a purely academic point of view. Halogen adsorbates are ideal for structural studies because they form strong, directional, monovalent bonds to semiconductor surfaces. As a result of their large electronegativities, halogens withdraw an appreciable amount of charge from a neighboring atom in forming a bond. This high degree of charge transfer facilitates the use of several surface-sensitive techniques. For example, core-level spectroscopies, such as soft X-ray photoelectron spectroscopy (SXPS), are used extensively in investigating the chemistry of halogen-semiconductor reactions, since bonding to halogens induces large, easily detectable chemical shifts in the binding energies of the substrate core electrons (76). Reactive molecular beam scattering has also been applied successfully to these systems, as halogen-semiconductor reactions typically generate a variety of volatile products (41).

There are several excellent reviews in print regarding halogen adsorption and halogen-semiconductor reactions. Various aspects of halogen adsorption on metal surfaces are reviewed by Dowben (77) and Jones (78); their reviews cover investigations prior to 1988. Winters \& Coburn (70) surveyed investigations of Si etching up to 1992. Yu \& DeLouise (41) reviewed more recent work on semiconductor surface chemistry, with particular emphasis on the use of molecular beam scattering techniques. The aim of the present review is to complement this work by summarizing what is known about halogen adsorption and reaction on III-V semiconductor surfaces in UHV. Note that because Yu 
\& DeLouise (41) have already presented an excellent discussion of $\mathrm{Cl}_{2}$ molecular beam scattering experiments on GaAs, those investigations receive less emphasis here.

Although this review is definitely motivated by the technological importance of semiconductor etching reactions, its focus is on the more fundamental aspects of the reactions, i.e. those with more of an academic emphasis and less of a directly applied nature. In particular, this work reviews what is currently understood about the basic chemical reactions of simple molecular halogens on III-V semiconductor surfaces and the properties of the surfaces following reaction. For the most part, the investigations of these systems naturally divide into three categories: geometric structure, electronic structure, and chemistry. Hence, this review is organized along these lines. The first two sections summarize what is known about the geometric and electronic structure of the surfaces. The third section discusses what is known about the chemistry of molecular halogen $\left(\mathrm{XeF}_{2}, \mathrm{Cl}_{2}, \mathrm{Br}_{2}, \mathrm{I}_{2}\right)$ reactions on III-V (GaAs, GaSb, InP, InAs, InSb) surfaces and is divided into subsections describing each halogen reactant separately.

\section{GEOMETRIC STRUCTURE}

The low index faces of GaAs and other III-V materials exhibit a range of complex clean-surface reconstructions. The (110) face, which is the natural cleavage plane for III-V single crystals, contains equal amounts of both elements and has the simplest reconstruction, with a $1 \times 1$ unit cell (79). Because of the ease of reproducibility of the $1 \times 1$ reconstruction and the fact that the Fermi level is unpinned on this surface, the (110) face has been extensively studied. The polar (001) face can be either group-III or group-V terminated, and its surface reconstructions, which often consist of ordered arrangements of dimers, are determined primarily by the stoichiometry of the near-surface region. Sputtering and annealing $\mathrm{GaAs}(001)$ in vacuum, for example, typically results in a Ga-rich surface having a $4 \times 6$ unit cell, while sputtering $\operatorname{InSb}(001)$ and $\operatorname{InAs}(001)$ generates an In-rich $\mathrm{c}(8 \times 2)$ surface $(80,81)$. Other $(001)$ reconstructions, such as $\mathrm{c}(4 \times 4)$ or $\mathrm{c}(2 \times 8)$, can be grown using molecular beam epitaxy (MBE) $(82,83)$. The polar (111) surface is also either group-III or group-V terminated. Both $(2 \times 2)$ and $(\sqrt{19} \times \sqrt{19})$ reconstructions have been observed for clean GaAs(111), depending on the surface composition (84).

Halogens often form an ordered overlayer on semiconductor surfaces. $\mathrm{Cl}_{2}$ has been observed, in some cases, to form a $1 \times 1$ overlayer on $\operatorname{GaAs}(110)$ (85-87), GaAs(001)-c(8 × 2) (87), InSb(001)-4 × 1 (88), and $\operatorname{InP}(001)-4 \times$ 2 (19). At other times, however, $\mathrm{Cl}_{2}$ adsorption leads to the complete removal of the low-energy electron diffraction (LEED) pattern, thereby indicating that the surface has become disordered. This has been seen for $\mathrm{Cl}_{2}$ adsorption 
on $\operatorname{GaAs}(110)$ (89), on $\operatorname{InP}(110)(90)$, and on $\operatorname{InP}(001)-4 \times 2$ (19). The adsorption of $\mathrm{I}_{2}$ on many surfaces-including $\mathrm{InSb}(001)-4 \times 1$ (88), $\operatorname{InSb}(001)$ $\mathrm{c}(4 \times 4)(88), \operatorname{InSb}(001)-\mathrm{c}(8 \times 2)(80,91,92), \mathrm{GaAs}(001)-4 \times 1(81,93$, 94), GaAs(001)-4 × $6(81,93,94), \operatorname{GaAs}(001)-\mathrm{c}(2 \times 8)(81,93,94)$, and $\operatorname{InAs}(001)-\mathrm{c}(8 \times 2)(81,93,94)$-relaxes the clean surface reconstruction and forms a highly ordered $1 \times 1$ overlayer.

Much can be learned by following how the LEED pattern changes as a result of halogen adsorption. For example, Varekamp et al (93) describe in detail the coverage dependence of the LEED pattern for $\mathrm{I}_{2}$ adsorption on $\mathrm{GaAs}(001)$ $4 \times 6$, which is representative of $I_{2}$ adsorption on several other surfaces. Small $\mathrm{I}_{2}$ exposures simply increase the background intensity without changing the $4 \times 6$ pattern, suggesting that the iodine initially adsorbs randomly on the surface. Larger exposures further increase the background and remove the higher-order LEED spots. Following sufficiently large exposures, the $1 \times 1$ LEED spots become more intense than the original $4 \times 6$ spots. Additional $\mathrm{I}_{2}$ exposure causes no further change in the LEED pattern, indicating saturation. The intense $1 \times 1$ pattern and the lack of any higher-order spots suggest that, at saturation, both the iodine overlayer and the substrate are ordered within a $1 \times 1$ unit cell.

Scanning tunneling microscopy (STM) is also an extremely useful technique for structural studies. STM provides local surface geometric information at the atomic level $(\sim 1 \AA)$ and morphological information at larger length scales $(\sim 25 \AA)$. Unfortunately, there have been only a handful of STM studies, to date, of halogenated III-V surfaces.

Patrin and coworkers $(95,96)$ investigated the adsorption of $\mathrm{Cl}_{2}$ and $\mathrm{Br}_{2}$ on GaAs(110) by using STM. They observed three types of local bonding configurations for both bromine and chlorine. These configurations are illustrated in Figure 1 and labeled A-type, B-type, and C-type. The A-type features, which are the most prevalent, form $\sim 1$ - $\AA$ high islands and are identified, in the case of chlorine, as $\mathrm{Cl}$ bonded to Ga sites. The B-type sites are located directly above As atoms, within A-type islands, and are identified with $\mathrm{Cl}$ bonded to As. The C-type sites, which are the least populated, have been assigned to $\mathrm{AsCl}_{2}$ species (97). Since $\mathrm{Br}_{2}$ and $\mathrm{Cl}_{2}$ exhibit similar adsorption behavior, the same interpretation of these three features was made for $\mathrm{Br}$ as for $\mathrm{Cl}$.

The only other atomic scale STM study, to date, of halogen adsorption on a III$\mathrm{V}$ semiconductor is by Varekamp et al $(93,94)$, who investigated $\mathrm{I}_{2}$ adsorption on $\operatorname{InSb}(001)-c(8 \times 2)$. In those studies, the STM images of an $\mathrm{I}_{2}$-saturated surface were found to exhibit an ordered square lattice of spots separated by $4.6 \AA$ in both the [110] and [ $\overline{1} 10]$ directions, which agrees with the size of the $\mathrm{InSb}(001)$ surface unit cell. These spots, which are presumably responsible 

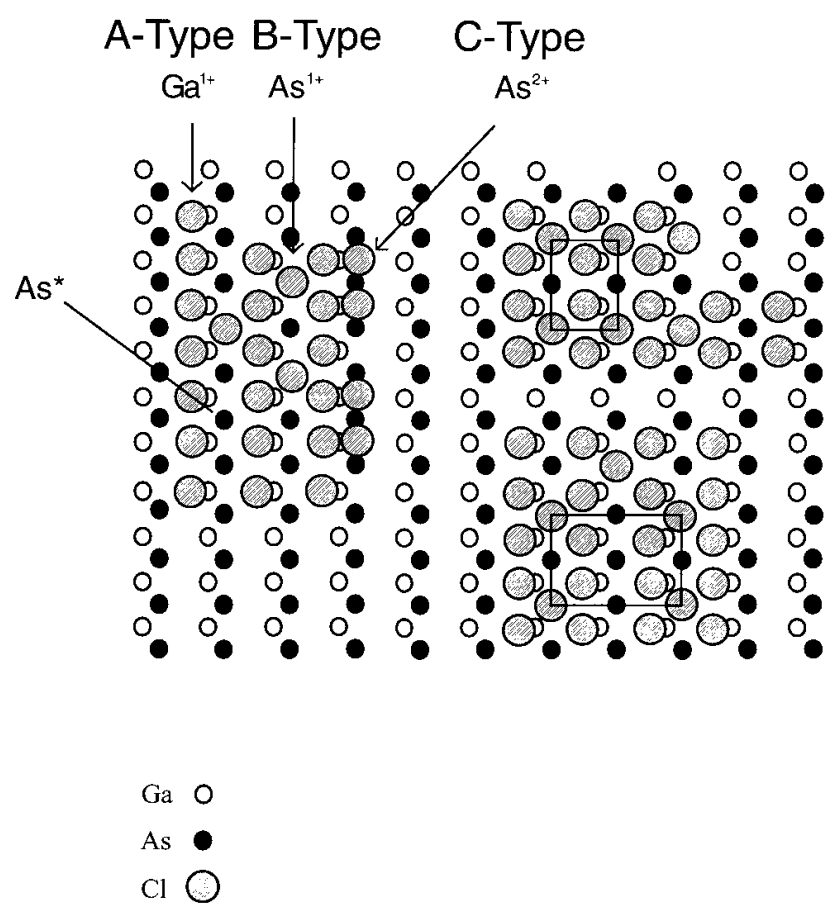

Figure 1 A model depicting the adsorption sites for $\mathrm{Br}$ and $\mathrm{Cl}$ on $\mathrm{GaAs}(110)$. The A-type islands, which have halogen-induced features within the rectangle formed by four As atoms, are identified with $\mathrm{Ga}-\mathrm{Cl}$ bonds. The B-type features, which are located above As atoms, are identified with As-Cl bonds. C-type features, which are observed in pairs along the edges of A-type islands, are identified as $\mathrm{AsCl}_{2}$ species. The $\mathrm{As}^{*}$ features are As atoms whose core-level binding energies are affected by nearby Cl-bound Ga atoms in the A-type islands. (From Reference 97.)

for the $1 \times 1$ LEED pattern, were interpreted as iodine atoms bonded atop the outermost substrate atoms. Pairs of brighter spots, oriented along the [110] azimuth and separated by $5.8 \AA$, were also visible in the STM images. These pairs were tentatively identified as iodine atoms bonded to unbroken In dimers on the surface.

In addition to investigating the local chemisorption geometry of bromine and chlorine on GaAs(110), Patrin and coworkers $(95,96)$ also looked at the etch-induced morphological changes that occur as a result of reaction. In this regard, $\mathrm{Cl}_{2}$ and $\mathrm{Br}_{2}$ were found to have identical effects. Reaction at temperatures below $\sim 550 \mathrm{~K}$ results primarily in halogen adsorption, either in two-dimensional islands or one-dimensional chains. Reaction at $\sim 625 \mathrm{~K}$ and above results instead in etching. Between 625 and $725 \mathrm{~K}$, the reaction generates 
rectangular single-layer etch pits and, at higher exposures, results in simultaneous multilayer etching. Reaction at $\sim 725 \mathrm{~K}$ and above is characterized by single-height-step retreat and triangular double-layer etch pit formation. Examples of the morphologies that result from etching $\mathrm{GaAs}$ with $\mathrm{Br}_{2}$ under various conditions are shown in Figure 2. Varekamp et al (93) observed similar etchinduced morphologies, i.e. rectangular etch pits and jagged step edges, in the room-temperature reaction of $\mathrm{InSb}(001)$ with $\mathrm{I}_{2}$.

\section{ELECTRONIC STRUCTURE}

In this section we describe what is known about the electronic structure of halogenated III-V semiconductor surfaces. First we outline the results of valenceband measurements, then we summarize core-level spectroscopy investigations.

\section{Valence Bands}

The most direct way in which to investigate the electronic structure of a surface is with photoelectron spectroscopy, which probes the filled electronic states. The system that has attracted the most attention, in terms of the collection and interpretation of valence-band photoelectron spectra, is chlorinated GaAs(110). Angle-integrated valence-band spectra of $\mathrm{Cl}_{2}$-reacted $\mathrm{GaAs}(110)$ show that the adsorption of chlorine generates an increase in intensity $\sim 3.5-6.0 \mathrm{eV}$ below the valence-band maximum (VBM), and this increase is associated with the $\mathrm{Cl}$ $3 p$ level $(89,98-102)$. High-resolution angle-resolved measurements by Margaritondo et al (85) indicate that there are actually five spectral features in the valence band, roughly 2.0, 4.5, 5.0, 6.5, and $8.0 \mathrm{eV}$ below the VBM. The band structure derived from Margaritondo et al's data has a $1 \times 1$ symmetry. Combined with independent LEED measurements, this $1 \times 1$ symmetry indicates that the periodicity of the $\mathrm{Cl}$ overlayer is in registry with the substrate, with delocalized electronic states that have the same symmetry as the substrate. Empirical tight-binding model calculations (85) and calculations based on the charge self-consistent extended Hückel method (103) compare well with the data if it is assumed that $\mathrm{Cl}$ bonds to As sites. In fact, the data were originally interpreted to mean that $\mathrm{Cl}$ bonds only to As, and not to Ga. However, more recent calculations using the linear combination of atomic orbitals (LCAO) approach match best to the experimental data for $\mathrm{Cl}$ bonded solely to $\mathrm{Ga}$ sites (104) or, possibly, to a mixture of Ga and As sites (105).

Chlorine generates similar valence-band features on other III-V (110) surfaces as well. Margaritondo et al (85) studied chlorine chemisorption on $\mathrm{GaSb}(110)$ and $\mathrm{InSb}(110)$. Some of the results of that work are shown in Figure 3. The adsorption of chlorine on all three surfaces has essentially the same effect, i.e. it generates an intense feature about $4.5 \mathrm{eV}$ below the VBM, 
(a)

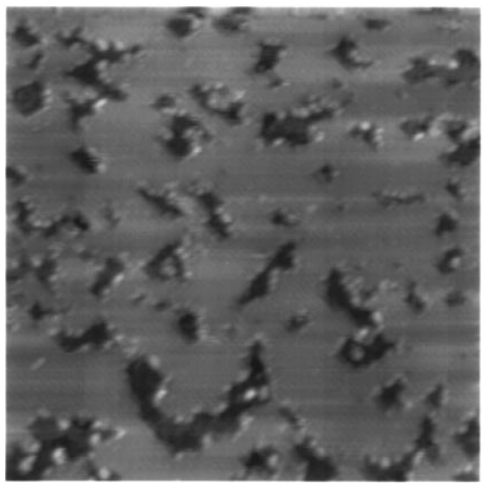

(c)

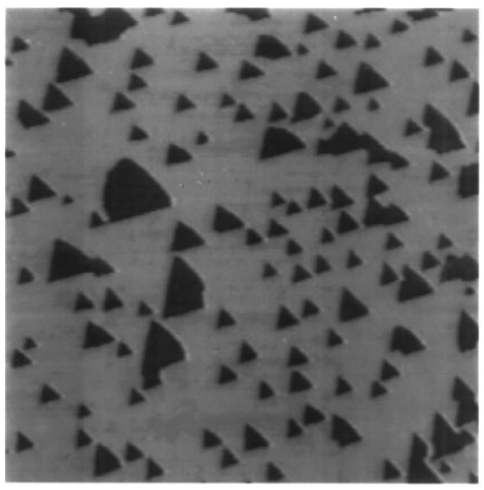

(b)

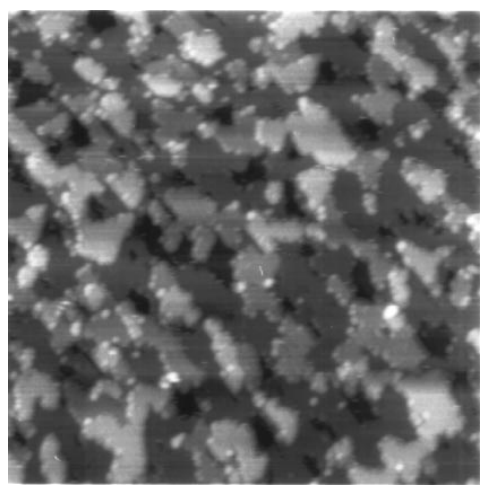

(d)

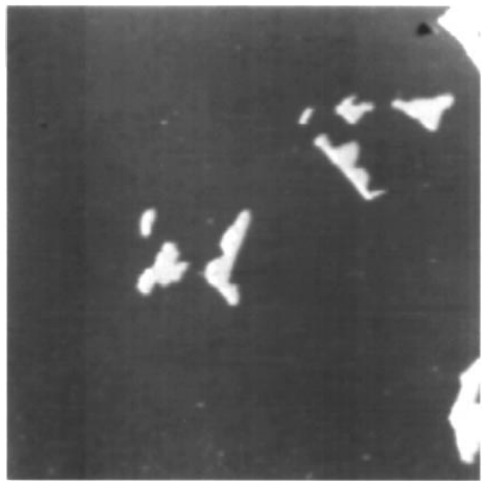

Figure 2 (a) A $450 \AA \times 450 \AA$ STM image of $\mathrm{GaAs}(110)$ after exposure to $0.36 \mathrm{~mA} \cdot \mathrm{s}$ of $\mathrm{Br}_{2}$ at $625 \mathrm{~K}$, showing etch pits that are one layer deep. Note that the units of exposure are in terms of the integrated current of a solid-state electrochemical cell, which was used to deliver the $\mathrm{Br}_{2}$. (b) An $850 \AA \times 850 \AA$ image after a $1.8 \mathrm{~mA} \cdot \mathrm{s} \mathrm{Br} 2$ exposure at $635 \mathrm{~K}$, showing five different substrate layers. (c) A $3000 \AA \times 3000 \AA$ image of an extended terrace following exposure to $0.7 \mathrm{~mA} \cdot \mathrm{s}$ of $\mathrm{Br}_{2}$ at $725 \mathrm{~K}$, showing triangular double-layer etch pits. (d) A $2000 \AA \times 2000 \AA$ image after a $1.8 \mathrm{~mA} \cdot \mathrm{s}$ exposure to $\mathrm{Br}_{2}$ at $725 \mathrm{~K}$, showing almost complete removal of a $\mathrm{GaAs}$ double-layer. (From Reference 95.) 
along with several other less prominent features. Table 1 is a summary of the peak positions indicated in Figure 3. Valence-band spectra from $\mathrm{Cl}_{2}$-reacted $\mathrm{InP}(110)$, for small exposures, also contain a Cl-induced peak located $4.4 \mathrm{eV}$ below the VBM, although, after higher exposures, the position of this peak shifts to $5.6 \mathrm{eV}$ and another appears at $8.9 \mathrm{eV}(90)$.

Angle-resolved valence-band spectra collected from a $1 \times 1$ iodine overlayer on $\operatorname{GaAs}(001)-4 \times 1, \operatorname{GaAs}(001)-\mathrm{c}(2 \times 8)$, and $\operatorname{InAs}(001)-\mathrm{c}(8 \times 2)$ all contain the same high-intensity dispersive surface state located $4.4 \mathrm{eV}$ below the VBM (81). Because this state has properties similar to those observed for a $1 \times 1$ $\mathrm{Cl}$ overlayer on the (110) surfaces of GaAs, GaSb, and $\mathrm{InSb}(85)$-i.e. a high relative intensity, a binding energy of $\sim 4.5 \mathrm{eV}$, and an insensitivity to the polarization of the incident light (s- vs p-polarization) - it was suggested that all these surface states have similar origins. Curiously, these states have greater intensity when the polarization of the incident radiation is along the [110] azimuth, as compared to the $[\overline{1} 10]$ azimuth. Also, this state forms following $I_{2}$ adsorption on both Ga-terminated GaAs(001)-4 $\times 1$ and As-terminated GaAs(001)$c(2 \times 8)$ and is thus apparently independent of the surface termination. Because of this independence, it cannot be attributed exclusively to either Ga-I or As-I bonding, but instead is identified as arising from a delocalized state of the

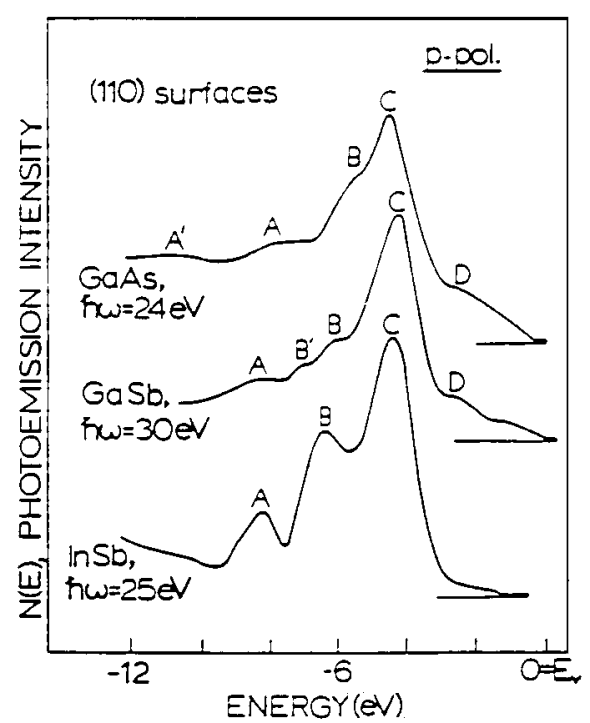

Figure 3 Angle-integrated valence-band spectra of chlorinated $\operatorname{GaAs}(110), \mathrm{GaSb}(110)$, and InSb(110). (From Reference 99.) 
Table 1 Experimental energy positions of the spectral peaks for $\mathrm{Cl}$-covered surfaces ${ }^{\mathrm{a}}$

\begin{tabular}{lccc}
\hline \hline Peak & $\mathrm{GaAs}(110)+\mathrm{Cl}$ & $\mathrm{GaSb}(110)+\mathrm{Cl}$ & $\mathrm{InSb}(110)+\mathrm{Cl}$ \\
\hline $\mathrm{A}^{\prime}$ & $11.3 \pm 0.5$ & - & - \\
$\mathrm{A}$ & $7.7 \pm 0.4$ & $8.3 \pm 0.2$ & $8.15 \pm 0.3$ \\
$\mathrm{~B}$ & $5.6 \pm 0.3$ & $7.2 \pm 0.2$ & $6.4 \pm 0.2$ \\
$\mathrm{~B}^{\prime}$ & - & $6.1 \pm 0.2$ & - \\
$\mathrm{C}$ & $4.6 \pm 0.4$ & $4.3 \pm 0.4$ & $4.2 \pm 0.3$ \\
$\mathrm{D}$ & $2.0 \pm 0.4$ & $3.5 \pm 0.4$ & - \\
$\mathrm{D}^{\prime}$ & - & $0.7 \pm 0.4$ & - \\
\hline
\end{tabular}

${ }^{\mathrm{a}}$ From Reference 99.

iodine overlayer itself. Note that not all $\mathrm{I}_{2}$-reacted III-IV surfaces exhibit this $4.5-\mathrm{eV}$ feature. On $\operatorname{InSb}(001)-\mathrm{c}(8 \times 2)$, a $1 \times 1$ iodine overlayer is observed that instead exhibits two valence-band features at $\sim 3 \mathrm{eV}$ and $6.4 \mathrm{eV}$ below the $\operatorname{VBM}(80,91,92)$.

Fluorinated $\mathrm{GaAs}(110)$ and $\mathrm{GaAs}(001)$ exhibit a very intense $\mathrm{F} 2 \mathrm{p}$ valenceband feature $\sim 8 \mathrm{eV}$ below the GaAs VBM, which persists throughout the reaction (106-108). Because these overlayers are not ordered, however, there would be no dispersion of the valence-band states. By comparing high-resolution valence-band and low-resolution electron energy loss measurements, Varekamp et al (108) determined the band line-up of $\mathrm{GaF}_{3}$ films grown on GaAs via reaction with $\mathrm{XeF}_{2}$. The $\mathrm{GaF}_{3} \mathrm{VBM}$ is $5.4 \mathrm{eV}$ below that of GaAs, and the $\mathrm{GaF}_{3}$ conduction band minimum (CBM) is $3 \mathrm{eV}$ above the CBM of GaAs.

The adsorption of halogens on a III-V semiconductor surface changes the position of the Fermi level at the surface. On GaAs(110), the adsorption of $\mathrm{Cl}_{2}(109), \mathrm{Br}_{2}$ (110), or $\mathrm{I}_{2}$ (109) each has basically the same effect. Namely, following small halogen exposures, the Fermi level for n-type substrates moves down to a position $0.2-0.3 \mathrm{eV}$ above the $\mathrm{VBM}$, whereas for p-type substrates it is pinned $\sim 0.1 \mathrm{eV}$ above the VBM. After large exposures, the Fermi level is pinned $\sim 0.5 \mathrm{eV}$ above the VBM, independent of doping. Similar effects are seen for both $\mathrm{XeF}_{2}$ reacted with $\mathrm{GaAs}(110)$ and $\mathrm{Cl}_{2}$ reacted with $\operatorname{InAs}(110)$, where, following sufficiently large exposures, the Fermi level is pinned $\sim 0.5 \mathrm{eV}$ above the VBM, independent of doping $(111,112)$. In several of the studies, this behavior was explained in terms of adsorbate-induced virtual gap states (ViGSs) $(102,109,110,112)$.

\section{Core Levels}

Core-level photoelectron spectroscopy is one of the best ways in which to probe halogen-surface reactions. Halogen atoms withdraw an appreciable amount of valence electronic charge in forming a bond as a result of their high 
electronegativity. This withdrawal of charge changes the potential felt by the core electrons, thereby causing an increase in their measured binding energies, typically on the order of $1 \mathrm{eV}$ per attached halogen atom. Core-level shifts also increase in a nearly linear fashion with the number of attached halogens (76), which makes the identification of chemically shifted core-level components fairly straightforward. Shifts observed in the core-level binding energies of various III-V substrate atoms, as a result of halogen adsorption, are given in Table 2. A proper identification of the source of each core-level component is required in order to use core-level spectroscopy to probe the chemistry of reacted surfaces. The chemical information obtained from these core-level investigations is presented in the chemistry section below.

Core-level binding energy shifts sometimes arise from reaction products other than surface halides. In studying the reaction of $\mathrm{XeF}_{2}$ with $\mathrm{GaAs}(110)$, Simpson et al (106) observed that fluorination induced an additional As $3 \mathrm{~d}$ component that was shifted $0.5 \mathrm{eV}$ higher in binding energy than bulk GaAs. For reaction at temperatures below $550 \mathrm{~K}$, this can be attributed simply to monofluorinated As atoms. However, following reaction at $550 \mathrm{~K}$, the $0.5-\mathrm{eV}$-shifted component persists even though there is no fluorine on the surface. This, along with the fact that the binding energy shift of As adsorbed onto GaAs is $\sim 0.5 \mathrm{eV}$ (113115 ), led to the conclusion that for reaction at $550 \mathrm{~K}$ and above, the additional As $3 \mathrm{~d}$ component is due to elemental As on the surface. Moreover, elemental As may also contribute to the intensity of the $0.5-\mathrm{eV}-$ shifted component

Table 2 Core-level binding energy shifts for various species on halogenated III-V semiconductor surfaces

\begin{tabular}{|c|c|c|c|c|c|}
\hline Absorbate & Substrate & Core-level & Moiety & Shift (eV) & References \\
\hline \multirow[t]{3}{*}{$\mathrm{F}$} & \multirow[t]{3}{*}{ GaAs(110), (001) } & \multirow[t]{2}{*}{$\mathrm{Ga} 3 \mathrm{~d}$} & $\mathrm{GaF}$ & $0.8-1.6$ & \multirow[t]{3}{*}{$106-108,111$} \\
\hline & & & $\mathrm{GaF}_{3}$ & $1.6-2.6$ & \\
\hline & & As $3 d$ & $\mathrm{AsF}$ & $0.4-0.5$ & \\
\hline \multirow[t]{4}{*}{$\mathrm{Cl}$} & \multirow[t]{4}{*}{ GaAs(110), (001) } & \multirow[t]{2}{*}{$\mathrm{Ga} 3 \mathrm{~d}$} & $\mathrm{GaCl}$ & $0.6-0.9$ & \multirow{4}{*}{$\begin{array}{c}86,89,97 \\
101,116,120\end{array}$} \\
\hline & & & $\mathrm{GaCl}_{2}$ & $1.7-1.8$ & \\
\hline & & \multirow[t]{2}{*}{ As $3 d$} & $\mathrm{AsCl}$ & $0.4-0.5$ & \\
\hline & & & $\mathrm{AsCl}_{2}$ & $1.1-1.3$ & \\
\hline \multirow[t]{5}{*}{$\mathrm{Br}$} & \multirow[t]{5}{*}{$\operatorname{GaAs}(110)$} & \multirow[t]{2}{*}{ Ga $3 d$} & $\mathrm{GaBr}$ & 0.32 & \multirow[t]{5}{*}{121} \\
\hline & & & $\mathrm{GaBr}_{3}$ & 1.2 & \\
\hline & & \multirow[t]{3}{*}{ As $3 d$} & $\mathrm{AsBr}$ & 0.7 & \\
\hline & & & $\mathrm{AsBr}_{3}$ & 2.0 & \\
\hline & & & $\mathrm{AsBr}_{5}$ & 4.1 & \\
\hline \multirow[t]{4}{*}{ I } & $\operatorname{GaAs}(001)$ & As $3 d$ & $\mathrm{AsI}_{2}$ & $0.9-1.0$ & \multirow[t]{4}{*}{93} \\
\hline & $\operatorname{InAs}(001)$ & In $4 d$ & InI & $0.48-0.52$ & \\
\hline & $\operatorname{InSb}(001)$ & In $4 d$ & InI & $0.38-0.54$ & \\
\hline & & $\mathrm{Sb} 4 \mathrm{~d}$ & $\mathrm{SbI}_{2}$ & 0.70 & \\
\hline
\end{tabular}


observed for reactions at lower temperature. A 0.5-eV-shifted As 3d component was also observed in spectra collected from chlorinated GaAs(110) (101). In the temperature range of $400-600 \mathrm{~K}$, there is no $\mathrm{Cl}$ remaining on the surface, yet the additional As $3 \mathrm{~d}$ component persists, leading in a similar way to its identification as elemental As. Finally, as part of an investigation of the room-temperature reaction of $\mathrm{Cl}_{2}$ with As-rich $\mathrm{GaAs}(110)$, Simpson et al (116) observed an anomalous low binding energy shift in the Ga $3 \mathrm{~d}$ core level. They suggested that this shifted component arose from Ga-Ga bonding, possibly in Ga dimers, clusters, or droplets.

Not only are directly induced chemical shifts detectable in core-level spectra, but so are contributions from other substrate atoms that have been disturbed as a result of halogen adsorption. As part of their SXPS study of the reaction of $\mathrm{Cl}_{2}$ with GaAs(110), Stepniak et al (97) observed an As 3d core-level component shifted $0.65 \mathrm{eV}$ to lower binding energy than bulk GaAs; they attributed this to As atoms located beneath $\mathrm{GaCl}$ islands (denoted As* in Figure 1). Subsequent theoretical investigations support the notion that $\mathrm{Cl}$ bonded to $\mathrm{Ga}$ can induce a shift to lower binding energy in a neighboring As atom. Using ab initio calculations, Corkhill \& Chelikowski $(117,118)$ showed that the attachment of $\mathrm{Cl}$ to a surface $\mathrm{Ga}$ site can cause the $\mathrm{Ga}$ atom to relax to a more bulk-like geometry, with a corresponding rearrangement of charge that affects neighboring As atoms in a manner consistent with a shift to lower binding energy. On the other hand, Khoo \& Ong (119), using semiempirical molecular-orbital calculations, showed that surface $\mathrm{Ga}$ atoms bonded to $\mathrm{Cl}$ can instead relax inwards, donating charge to surface As atoms (119). In either case, the bonding of $\mathrm{Cl}$ to a surface $\mathrm{Ga}$ atom is expected to indirectly induce a shift in the binding energy of the core electrons of nearby As atoms.

Tricoordinate atoms at or near the surface also have core-level binding energies different than the atoms comprising the bulk semiconductor. As a result of their reduced coordination number, the outermost atoms on a clean III-V surface are rehybridized to a more stable tricoordinate configuration. The charge rearrangement that accompanies this rehybridization induces core-level binding energy shifts in these surface atoms, which appear in an SXPS spectrum as surface-shifted core-level (SSCL) components. Values for some GaAs surface shifts are tabulated in Reference 120 and references cited therein. Curiously, spectra collected from GaAs surfaces heavily reacted with $\mathrm{Cl}_{2}$ (89) or $\mathrm{XeF}_{2}$ (106-108) exhibit SSCL components, even though no areas of unexposed surface remain. These unexpected core-level components were interpreted, first by Shuh et al (89) and later by Varekamp et al (108) and Simpson et al (106, 107), as arising from buried tricoordinate atoms that form as a result of the etching reaction. Shuh et al (89) argued that these atoms should have local bonding geometries similar to unreacted surface atoms and therefore should 
exhibit core-level binding energy shifts similar to those of the outermost atoms on a clean surface.

In addition to the substrate core levels, the adsorbate core levels sometimes exhibit chemically induced shifts. Shuh et al (89) noted that for $\mathrm{Cl}_{2}$ adsorbed on $\operatorname{GaAs}(110)$, two separate components are apparent in the $\mathrm{Cl} 2 \mathrm{p}$ spectrum, indicating that $\mathrm{Cl}$ is in two unique chemical arrangements. Simpson et al (120) made a similar observation of two $\mathrm{Cl} 2 \mathrm{p}$ components for chlorinated $\mathrm{GaAs}(001)$. In that study, however, a correlation was found between the appearance of the second $\mathrm{Cl} 2 \mathrm{p}$ component and the formation of surface dichlorides, i.e. $\mathrm{AsCl}_{2}$ and $\mathrm{GaCl}_{2}$. Thus, it was concluded that the second $\mathrm{Cl} 2 \mathrm{p}$ component arises from $\mathrm{Cl}$ atoms in dichloride species.

In their investigation of $\mathrm{Br}_{2}$ adsorption on $\mathrm{GaAs}(110), \mathrm{Gu}$ et al (121) observed two $\mathrm{Br} 3 \mathrm{~d}$ core-level components of nearly equal intensity, which they initially identified as $\mathrm{As}-\mathrm{Br}$ and $\mathrm{Ga}-\mathrm{Br}$ bonding. This assignment, however, could not be reconciled with later STM measurements carried out by the same group that showed a preference for $\mathrm{Ga}-\mathrm{Br}$ over As-Br bonding, which would not result in equal intensities of the two $\mathrm{Br} 3 \mathrm{~d}$ components (95).

A similar effect was also observed for $\mathrm{I}_{2}$-covered $\mathrm{GaAs}(001), \operatorname{InAs}(001)$, and $\mathrm{InSb}(001)$, which exhibited I $4 \mathrm{~d}$ core-level spectra that were clearly composed of two separate components (94). For these systems, the two components had nearly equal intensity at the saturation coverage, independent of the stoichiometry or the structure of the starting surface, indicating that they are not related to the difference between group-III and group-V bonding, but have some other origin. At this time, the origin of the two $\mathrm{Br} 3 \mathrm{~d}$ and the two I $4 \mathrm{~d}$ corelevel components is unknown and warrants further investigation. Varekamp et al (suggested, however, that these components may result from iodine attached at unbroken and broken surface dimers, thereby corresponding to the two structures seen with STM.

\section{CHEMISTRY}

Once the details of the relevant spectroscopies are worked out and the initial chemisorption is understood, emphasis can shift to the chemistry of the reactions. Although most studies to date have concentrated on the reaction of $\mathrm{Cl}_{2}$ with GaAs, owing to its technological importance, certain general trends are apparent for all of the reactions. For example, molecular halogens always dissociatively chemisorb on III-V surfaces. Also, the halogenation reactions appear to occur in a stepwise manner, with monohalides formed first, followed by di- and trihalide formation. The reactions are often sensitive to surface crystallinity, stoichiometry, and temperature; sometimes a surface becomes passivated by an ordered overlayer, whereas other times it etches. This 
section gives a brief summary of what is known, to date, about the complex chemistry of these surface reactions.

\section{Fluorine}

The development of microelectronic devices based on III-V semiconductor materials has been hindered by the lack of suitable insulators. Many attempts have been made in the past to find insulators that can be grown on GaAs and other III-V compounds, but none were particularly useful to the microelectronics industry (122). In order for an insulating material to be suitable for device fabrication, it must grow in a spatially homogeneous manner with an interface that is relatively free of gap states. Furthermore, the film growth method should be a simple, inexpensive chemical process that is similar in procedure to $\mathrm{SiO}_{2}$ growth on $\mathrm{Si}$ via exposure to $\mathrm{O}_{2}$. Recently, it was shown that a $10 \mathrm{eV}$ band gap insulator, $\mathrm{GaF}_{3}$, can be grown on $\mathrm{GaAs}$ via exposure to various fluorine-based compounds $(30,34,35,38,107,108,120,123-126)$. Operational devices have been constructed from $\mathrm{GaF}_{3}-\mathrm{GaAs}$ structures $(124,125,127-129)$, which demonstrates that the interface state density can be reduced to a sufficiently low level that $\mathrm{GaF}_{3}$ may be a suitable insulator for GaAs-based devices. Hence, because of its potential technological importance, the reaction of atomic $\mathrm{F}$ with GaAs has been studied recently.

There have been only a few fundamental studies of this reaction, however, all of which used $\mathrm{XeF}_{2}$ as a reactant $(106-108,111,130)$. The reaction of $\mathrm{XeF}_{2}$ with GaAs has been followed over a range of exposures and temperatures by using SXPS measurements $(106-108,111)$ and a combination of Auger electron spectroscopy (AES) and high-resolution electron energy loss spectroscopy (HREELS) (130) measurements. $\mathrm{XeF}_{2}$ is an excellent source of atomic $\mathrm{F}$, as it readily dissociates on a GaAs surface, thereby liberating $\mathrm{F}$ atoms without incorporating any $\mathrm{Xe}$ into the surface. These lone $\mathrm{F}$ atoms are highly reactive. Initially, they simply chemisorb on the surface, forming Ga and As monofluorides $(108,111,130)$. With sufficient disruption of the surface, however, there is a transition from chemisorption to etching $(111,130)$.

SXPS measurements revealed that the room-temperature fluorination of GaAs results in simultaneous etching and film growth, with the removal of As from the near-surface region accompanied by the build-up of a film of $\mathrm{GaF}_{3}(106-$ 108). The interface between the film and substrate is $\sim 5 \AA$ thick and consists of the intermediate reaction products: $\mathrm{GaF}, \mathrm{AsF}$, and/or $\mathrm{As}_{x}$, along with tricoordinate Ga and As defects $(106-108,111)$. Figure 4 shows typical SXPS spectra of the $\mathrm{Ga}$ and As $3 \mathrm{~d}$ core levels for a moderately fluorinated GaAs surface, with the contributions from each of these species indicated.

The etching/film-growth reaction is independent of the crystal face and the initial surface crystallinity (108), and it shows no dependence on the doping 


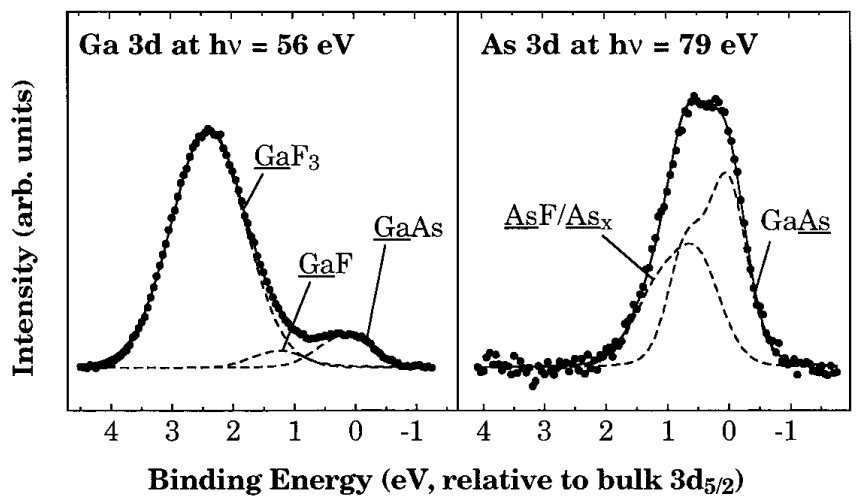

Figure $4 \mathrm{Ga}$ and As 3d core-level spectra collected from a moderately fluorinated GaAs surface. Dots are the background-subtracted raw data; dashed lines are the individual components, determined via numerical fitting; and the solid line is the sum of the components.

level of the substrate (130). Film growth is thought to occur via the diffusion of $\mathrm{F}$ to the interface to form $\mathrm{GaF}_{3}$ and via the diffusion of As from the interface to the surface, from where As desorbs $(106,107)$. In this way, the film actually grows down into the substrate and consumes $\mathrm{GaAs}$ to form $\mathrm{GaF}_{3}$. Figure 5 shows the amounts of $\mathrm{GaF}$ and $\mathrm{GaF}_{3}$ present on $\mathrm{GaAs}(110)$ as a function of $\mathrm{XeF}_{2}$ exposure, illustrating how a $\mathrm{GaF}_{3}$ film builds up with increasing fluorination.

The volatile reaction products have not yet been directly measured for the reaction of fluorine with GaAs. However, in direct analogy to the formation of $\mathrm{AsCl}_{3}$ in the reaction of $\mathrm{Cl}_{2}$ with GaAs, which has been measured $(4,131-134)$, it was proposed that $\mathrm{AsF}_{3}$ is the primary etch product for reactions at or near room temperature (106-108).

The reaction of fluorine with GaAs is thought to occur in a stepwise manner, i.e.

$$
\begin{array}{lc}
\mathrm{GaAs}+2 \mathrm{~F} \rightarrow \mathrm{GaF}+\mathrm{AsF}, & 1 . \\
\mathrm{GaF}+\mathrm{F} \rightarrow \mathrm{GaF}_{2}, & 2 \mathrm{a} . \\
\mathrm{AsF}+\mathrm{F} \rightarrow \mathrm{AsF}_{2}, & 2 \mathrm{~b} . \\
\mathrm{GaF}_{2}+\mathrm{F} \rightarrow \mathrm{GaF}_{3}, & 3 \mathrm{a} .
\end{array}
$$

and

$$
\mathrm{AsF}_{2}+\mathrm{F} \rightarrow \mathrm{AsF}_{3} .
$$


Assuming this to be true, the presence of surface AsF, along with the absence of any surface $\mathrm{AsF}_{2}$, indicates that Step $3 \mathrm{~b}$ (followed by the desorption of $\mathrm{AsF}_{3}$ ) is more rapid than Step $2 b$. The presence of $\mathrm{GaF}$ and $\mathrm{GaF}_{3}$ on the surface, combined with the absence of an appreciable amount of $\mathrm{GaF}_{2}$, also indicates that Step 3a is faster than Step 2a. Using this argument, researchers concluded that the disruption of the lattice required for Step 2 is what ultimately limits the reaction $(107,111)$. Note that measurements of the volatile reaction products would help to further support these conclusions.

Raising the substrate temperature during reaction increases the initial $\mathrm{F}$ uptake somewhat, but for temperatures up to $\sim 550 \mathrm{~K}$, the $\mathrm{GaF}_{3}$ film thickness is limited to $\sim 15 \AA(106)$. This thickness limit can be overcome, however, by increasing the $\mathrm{XeF}_{2}$ pressure by several orders of magnitude (106). Reaction at temperatures above $\sim 550 \mathrm{~K}$ leads to removal of both $\mathrm{Ga}$ and As, resulting in a surface covered by approximately one monolayer (ML) of excess As. Annealing $\mathrm{a} \mathrm{GaF}_{3}$-covered surface, however, leads to the inhomogeneous removal of $\mathrm{GaF}_{3}$ molecules (108). The temperature dependence of the reaction of $\mathrm{XeF}_{2}$ with $\mathrm{GaAs}(110)$ is illustrated in Figure 6 for two exposures, 10 and $100 \mathrm{~kL}$ $\left(1 \mathrm{~kL}=10^{-3}\right.$ torr $\left.\cdot \mathrm{s}\right)$.

\section{Chlorine}

It is critically important, from a technological standpoint, to understand the interaction of chlorine with GaAs surfaces, since chlorine-based plasmas are the most commonly used to dry etch GaAs wafers during device manufacture. Chlorine is the etchant of choice for GaAs, as well as other III-V semiconductors,

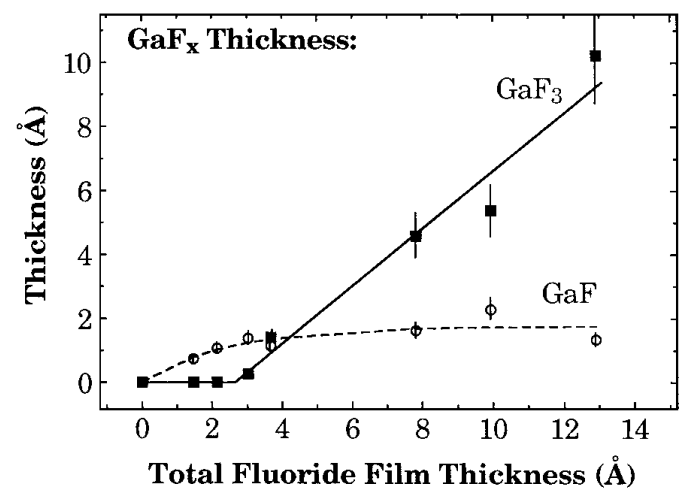

Figure 5 The amounts of $\mathrm{GaF}$ and $\mathrm{GaF}_{3}$ present on a fluorinated $\mathrm{GaAs}$ surface, as a function of total fluoride film thickness, derived from analysis of core-level SXPS spectra. (From Reference 107.) 


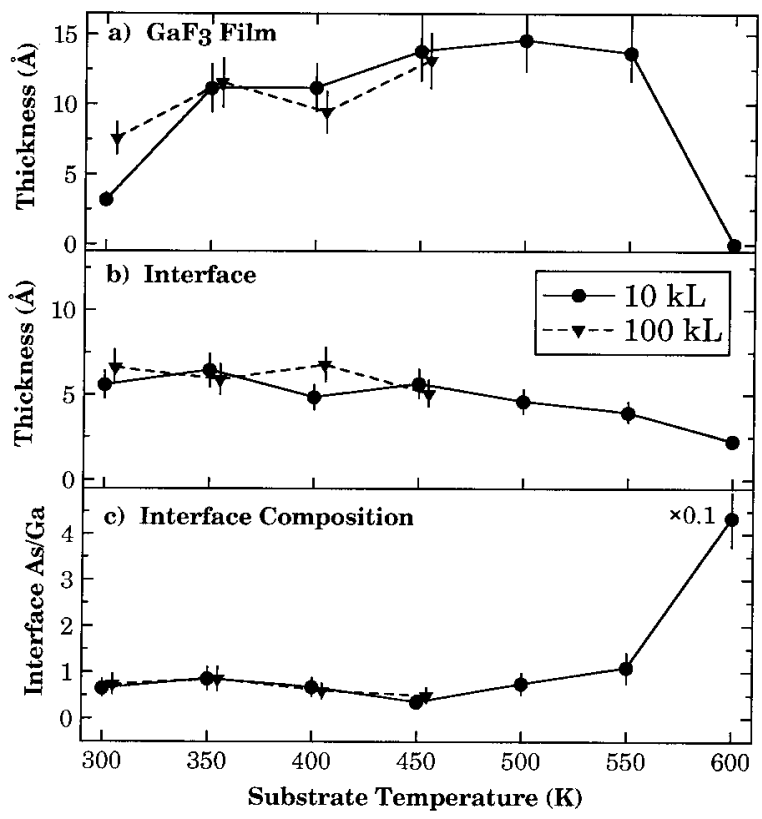

Figure $6 \mathrm{GaF}_{3}$ film thickness, interface thickness, and interface As/Ga ratio derived from analysis of core-level SXPS spectra are plotted as a function of substrate temperature for GaAs(110) exposed to 10 and $100 \mathrm{~kL}$ of $\mathrm{XeF}_{2}$. (From Reference 106.)

primarily because of the volatility of chlorides that are formed by the reaction. Although many techniques have been applied to investigate the fundamental reaction of $\mathrm{Cl}_{2}$ with GaAs, photoelectron spectroscopy and molecular beam scattering were used predominantly. The general findings of these experiments are given below.

There was originally some ambiguity as to whether chlorine had a preferred bonding site on $\operatorname{GaAs}(110)$. The first photoelectron spectroscopy studies of the room-temperature reaction of $\mathrm{Cl}_{2}$ with $\mathrm{GaAs}(110)$, by Margaritondo et al $(85,98,99)$, combined with tight-binding calculations, indicated that chlorine dissociatively chemisorbs on GaAs(110) and bonds preferentially to surface As atoms. After noting a core-level shift of the As $3 \mathrm{~d}$ level and no corresponding change in the Ga 3d level, Schnell et al (86) also concluded that $\mathrm{Cl}$ bonds primarily to As. Subsequent SXPS investigations of the Ga and As 3d core levels by Shuh et al (89), Stepniak et al (97), and Simpson et al (101), however, showed that $\mathrm{Cl}$ bonds equally well to both $\mathrm{Ga}$ and $\mathrm{As}$ on the (110) surface. The discrepancy in these results is likely due to poorer resolution in the earlier work 
(86), which made it difficult to resolve the shifted Ga 3d component. From an analysis of chlorine electron-stimulated desorption (ESD) from chlorinated GaAs(110), Troost et al (135) also found evidence for two different binding sites, which were attributed to $\mathrm{Ga}-\mathrm{Cl}$ and As-Cl. Using HREELS and AES, Pankratz et al (136) found that on $\mathrm{GaAs}(110), \mathrm{Cl}$ bonds to Ga atoms initially, but that when etching ensues, $\mathrm{Cl}$ also bonds to As atoms.

Researchers have recently gained some insight into these apparently contradictory results, some of which suggest that $\mathrm{Cl}_{2}$ passivates $\mathrm{GaAs}(110)$ at room temperature, while others indicate spontaneous etching. Sullivan et al (87) found, using molecular beam scattering, that $\mathrm{GaAs}(110)$ saturates at room temperature with $\sim 0.5 \mathrm{ML}$ of $\mathrm{Cl}$ adsorbed. This finding is consistent with the earliest photoelectron spectroscopy investigations $(85,86,98,99)$ but contradicts later core-level SXPS investigations that show that $\mathrm{Cl}_{2}$ etches $\mathrm{GaAs}(110)$ at room temperature $(89,101)$. An SXPS experiment that repeated the sample preparation technique used by Sullivan et al (which generates a slightly As-rich surface) showed that the surface does appear to passivate with $\sim 0.5 \mathrm{ML}$ of $\mathrm{Cl}$ adsorbed, principally as $\mathrm{AsCl}$, but that sufficiently large $\mathrm{Cl}_{2}$ exposures $(>5 \times$ $10^{4}$ Langmuirs) do induce etching on this surface (116). Both Sullivan et al (87) and Simpson et al (116) suggested that surface defects play a role in determining whether a surface passivates or etches. Simpson et al further suggested that excess As can tie up these defect sites, thereby stabilizing the surface against chlorine attack. Hence, crystallinity and stoichiometry both appear to directly affect the path that the reaction of $\mathrm{Cl}_{2}$ with $\mathrm{GaAs}(110)$ follows, at least initially, so one must be careful to fully characterize the starting surface if results from different experiments are to be compared. Furthermore, although under certain conditions there appear to be preferred binding sites and passivation, chlorine ultimately does etch $\mathrm{GaAs}(110)$ at room temperature and bonds to both $\mathrm{Ga}$ and As in the process.

The composition and structure of the initial clean surface affects reactions on $\operatorname{GaAs}(001)$ as well. Using a combination of metastable quenching electron spectroscopy (MQS), AES, LEED, and temperature-programmed desorption (TPD), Ludviksson et al (137) showed that chlorinating Ga-rich GaAs(001)$\mathrm{c}(8 \times 2)$ at $85 \mathrm{~K}$ generates a stable $\mathrm{GaCl}$ overlayer but that chlorinating an As-rich surface instead forms As chlorides. Sullivan et al (87) showed, through a series of molecular beam scattering experiments, that a similar effect occurs at room temperature. Namely, Ga-rich $\operatorname{GaAs}(001)-\mathrm{c}(8 \times 2)$ is passivated by a layer of $\mathrm{GaCl}$, but As-rich $\mathrm{GaAs}(001)-\mathrm{c}(2 \times 8)$ exhibits continuous $\mathrm{Cl}_{2}$ uptake, which is indicative of etching. Using SXPS, Simpson et al (120) determined that following room-temperature chlorination, As-rich GaAs(001) surfaces initially form more As chlorides, whereas Ga-rich surfaces initially form more 
Ga chlorides. Thus, chlorine simply bonds to whichever element is present at the surface. Mokler et al (138), using thermal desorption spectroscopy (TDS) and AES, and Simpson et al (120), using SXPS, found that the initial rate of $\mathrm{Cl}$ uptake is greater on Ga-rich surfaces. Mokler et al (138) further showed that a surface capped with $50 \AA$ of As was entirely unreactive to $\mathrm{Cl}_{2}$. In addition, Mokler et al (138) and Sullivan et al (87) showed that sputter-induced damage enhances the reactivity of a GaAs surface. Hence, there is a strong sensitivity to the stoichiometry and crystallinity of the starting surface for $\operatorname{GaAs}(001)$, with Ga-rich surfaces and surfaces with more defects being more reactive.

The chemisorption mechanism for $\mathrm{Cl}_{2}$ on $\mathrm{GaAs}$ has been investigated by a number of researchers. Using molecular beam scattering, DeLouise showed that the reaction is precursor mediated (139-141). Later, Flaum et al (142) showed that two processes are actually involved: direct chemisorption and precursor mediated chemisorption. Su et al (143) and Balooch et al (4) analyzed their data by using Langmuir adsorption kinetics, i.e.

$$
S(\theta)=a(b-\theta) .
$$

Sullivan et al (87) used molecular beam scattering to find that $\mathrm{Cl}_{2}$ does indeed appear to exhibit Langmuir adsorption behavior on Ga-rich GaAs(001)-c $(8 \times$ $2)$, As-rich GaAs(001)-c(2 × 8), and GaAs(110). However, Simpson et al $(116,120)$ later found from an analysis of SXPS data that the reaction of $\mathrm{Cl}_{2}$ with GaAs(110), with Ga-rich GaAs(001)-4 × 6, and with As-rich GaAs(001)$c(2 \times 8)$ and $-c(4 \times 4)$ surfaces instead appears to follow adsorption kinetics described by the Elovich equation,

$$
S(\theta)=a \exp (-b \theta)
$$

Although it has received considerable attention, the adsorption mechanism for chlorine on GaAs is still not entirely understood and requires further investigation.

Once the initial reaction has been characterized, the result of much larger $\mathrm{Cl}_{2}$ exposures can be investigated. One means of studying the etching reaction is to collect the volatile products created during the reaction. This is typically done through the use of molecular beam scattering techniques. To study the etching of $\mathrm{GaAs}$ by $\mathrm{Cl}_{2}$, for example, a beam of $\mathrm{Cl}_{2}$ is focused onto a $\mathrm{GaAs}$ surface and the unreacted $\mathrm{Cl}_{2}$ flux, as well as the flux of the various reaction products (e.g. $\mathrm{GaCl}_{x}, \mathrm{AsCl}_{x}, \mathrm{As}_{x}$ ), is collected to determine sticking coefficients, branching ratios for the various products, and etch rates (41).

For both $\mathrm{GaAs}(110)$ and $\mathrm{GaAs}(001)$, the temperature of the substrate directly affects the reaction rate (see Figure 7b) (143). From room temperature up to $\sim 400 \mathrm{~K}$, the etch rate increases roughly linearly with the substrate temperature. 
Between $450 \mathrm{~K}$ and $600 \mathrm{~K}$, the etch rate is constant. It increases with temperature between 600 and $700 \mathrm{~K}$, after which it again levels off.

There are changes in the surface composition, which were observed using SXPS (101), that correspond to the changes in etch rate. Up to $\sim 400 \mathrm{~K}, \mathrm{Cl}$ is stable on the surface, but for temperatures above $\sim 400 \mathrm{~K}$, no $\mathrm{Cl}$ remains on the surface following reaction. Instead, for temperatures between $\sim 400$ and $600 \mathrm{~K}$, an overlayer of As is formed. At $\sim 650 \mathrm{~K}$ and above, there is complete etching, with $\mathrm{Ga}$ and As removed stoichiometrically.

The changes in the etch rate and surface composition with temperature correlate with changes in the gas-phase product distribution, as might be expected
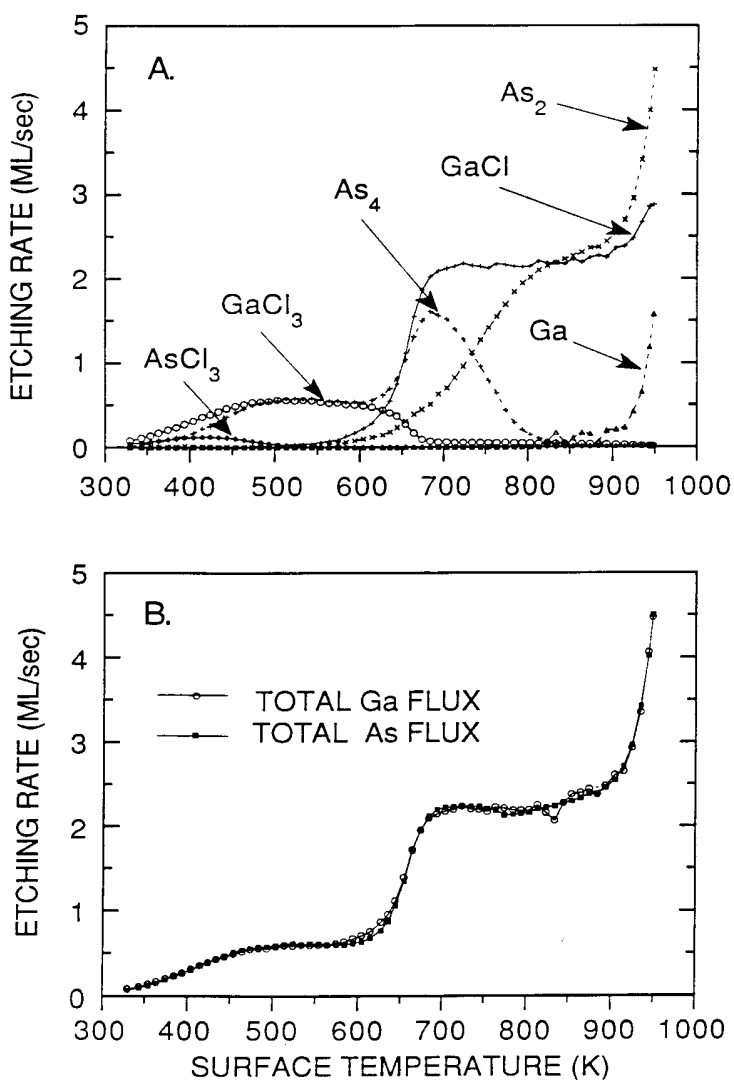

Figure 7 (a) The dependence of the steady-state GaAs etch rate on surface temperature for various reaction products, with a $\mathrm{Cl}_{2}$ flux of $2.8 \mathrm{ML} \cdot \mathrm{s}^{-1}$. (b) A comparison of the etch rates for $\mathrm{Ga}$ - and As-containing products. (From Reference 134.) 


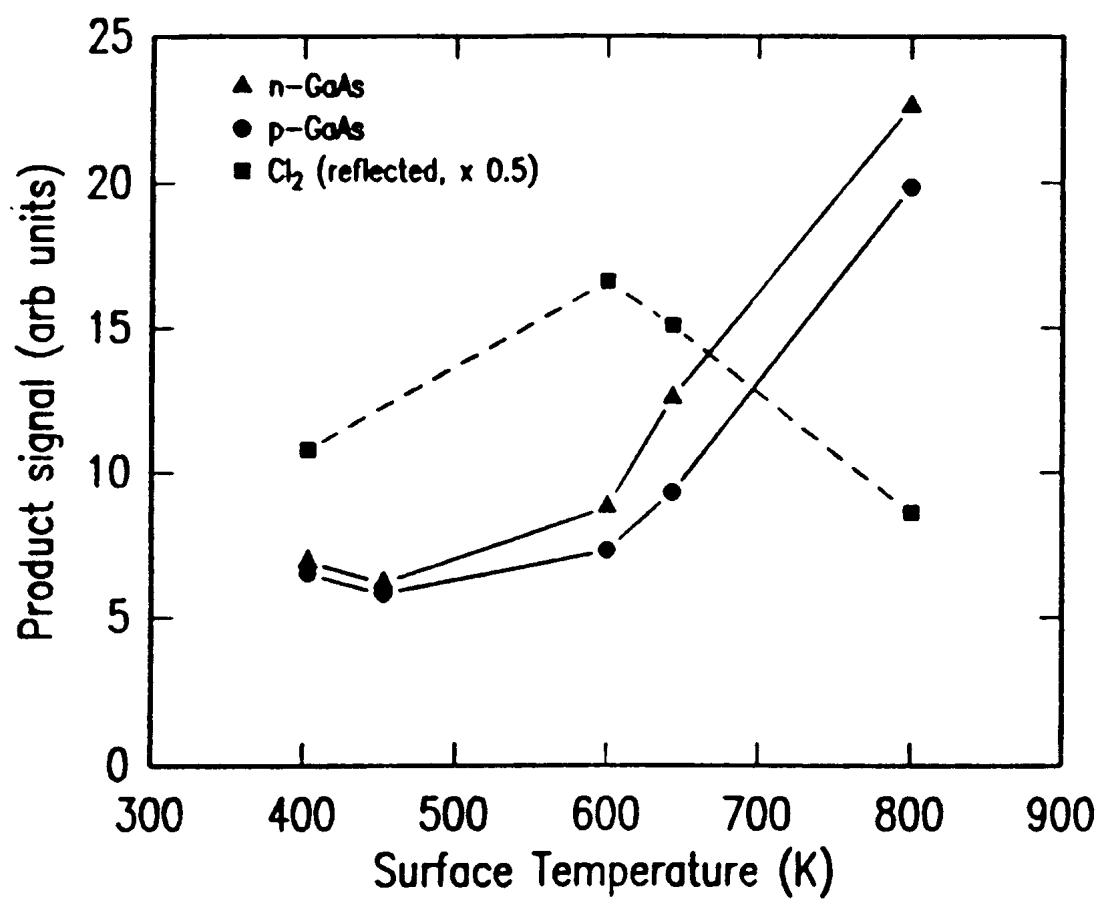

Figure 8 Temperature dependence of the etch rate of doped GaAs( $(001)$ reacted with a steady flux of $\mathrm{Cl}_{2}$. Also shown is the signal from the reflected, unreacted $\mathrm{Cl}_{2}$. (From Reference 132.)

(see Figure 7a) (143). Below $\sim 650 \mathrm{~K}$, the primary volatile etch products are $\mathrm{GaCl}_{3}$ and $\mathrm{AsCl}_{3}$. Above $\sim 650 \mathrm{~K}$, however, the principal etch products are instead $\mathrm{GaCl}$ and $\mathrm{As}_{2} / \mathrm{As}_{4}$. Gallium and arsenic trichlorides are the thermodynamically predicted products, given a sufficient $\mathrm{Cl}$ concentration, but $\mathrm{GaCl}$ and elemental As are the predicted products for a Cl-deficient situation (144). There is no significant change in the sticking probability of $\mathrm{Cl}_{2}$ at $\sim 650 \mathrm{~K}(142)$. There is, however, an increase in the desorption rate of $\mathrm{Cl}$-containing products (143), so the reaction becomes limited by the $\mathrm{Cl}$ concentration at elevated temperatures (139), and this is reflected in the gas-phase product distribution.

The reaction is also sensitive to the doping level of the GaAs substrate. Using molecular beam scattering, Houle (132) showed that the etch rate is independent of doping over the temperature range $400-550 \mathrm{~K}$ but that above $550 \mathrm{~K}$, n-type GaAs etches more rapidly than p-type (132). This is illustrated in Figure 8. Moreover, $\mathrm{n}$-type doping increases the amount of $\mathrm{AsCl}_{3}$ produced, as compared to $\mathrm{AsCl}_{2}$, whereas p-type doping enhances the formation of $\mathrm{GaCl}_{3}$ over $\mathrm{GaCl}_{2}$. 
Insight into the etching reaction is also gained by studying the composition of etched surfaces. From core-level photoelectron spectroscopy investigations, it was found that the etching reaction occurs in a step-wise manner $(89,97,116$, 120).

$$
\begin{aligned}
& \mathrm{GaAs}+2 \mathrm{Cl} \rightarrow \mathrm{GaCl}+\mathrm{AsCl} \\
& \mathrm{GaCl}+\mathrm{Cl} \rightarrow \mathrm{GaCl}_{2} \\
& \mathrm{AsCl}+\mathrm{Cl} \rightarrow \mathrm{AsCl}_{2} \\
& \mathrm{GaCl}_{2}+\mathrm{Cl} \rightarrow \mathrm{GaCl}_{3} \\
& \mathrm{AsCl}_{2}+\mathrm{Cl} \rightarrow \mathrm{AsCl}_{3} .
\end{aligned}
$$

In contrast to $\mathrm{GaF}_{3}, \mathrm{GaCl}_{3}$ is sufficiently volatile at room temperature that it does not build up on the surface. The principal products on the surface following room-temperature reaction are $\mathrm{AsCl}$ and $\mathrm{GaCl}_{2}(89,116,120)$, so either Step 7b or Step 8a is rate limiting. Since comparable amounts of both $\mathrm{AsCl}$ and $\mathrm{GaCl}_{2}$ build up on the surface, the slow rate of removal of one of them must be limiting the other. After considering the possible ways that this can occur, Simpson et al (116) argued that Step 8a is rate limiting in this reaction, in agreement with Shuh et al (89). In addition, after noting a correlation between the $\mathrm{AsCl}$ and $\mathrm{GaCl}_{2}$ coverage, Simpson et al (116) postulated the existence of an $-\mathrm{AsCl}-\mathrm{GaCl}_{2}$ tree-like structure similar to the fluorosilyl trees observed on heavily fluorinated Si surfaces (72). The presence of this structure was used to explain how the stability of $\mathrm{GaCl}_{2}$ could restrict further reaction of the $\mathrm{AsCl}$ moieties.

Finally, as discussed above, in addition to producing $\mathrm{Ga}$ and As chlorides, the reaction of $\mathrm{Cl}_{2}$ with $\mathrm{GaAs}$ also appears to generate subsurface tricoordinate atoms (89) that are identical in nature to those formed in the reaction of $\mathrm{XeF}_{2}$ with GaAs (106-108). Shuh et al (89) proposed that a measurable number of subsurface tricoordinate atoms are observed because of the stability of tricoordinate $\mathrm{Ga}$ and As atoms in the absence of crystal fields. For Ga, this stability is a simple consequence of it being a group-III element. For As, which is a group-V element, the two electrons not involved in bonding can pair up in a filled orbital, thereby stabilizing the configuration. In fact, $\mathrm{Ga}$ and As atoms are usually tricoordinately bonded on a clean GaAs surface. For reacted surfaces, bond breaking reduces the coordination number of otherwise tetracoordinate substrate atoms. These unreacted atoms can then rehybridize to the stable tricoordinate configuration. Hence, etching GaAs with either fluorine or chlorine 
generates these atoms naturally as part of the reaction. So far, these tricoordinate atoms have only been detected by using SXPS. Corroboration by other techniques is needed to confirm their existence.

A limited number of studies have investigated the reaction of chlorine with III-V substrates other than GaAs. The results of these investigations show that qualitative similarities exist for $\mathrm{Cl}_{2}$ reactions on all III-V substrates. Margaritondo et al (99) studied the chemisorption of $\mathrm{Cl}_{2}$ on $\mathrm{GaSb}(110), \operatorname{InSb}(110)$, and $\mathrm{GaAs}(110)$. In that study, which combined angle-integrated valence-band photoemission with tight-binding calculations, it was concluded that in all three cases $\mathrm{Cl}$ atoms bond preferentially to the anion and not to the cation. Since it was later shown, however, that $\mathrm{Cl}$ bonds to both $\mathrm{Ga}$ and $\mathrm{As}$ atoms on $\mathrm{GaAs}(110)$ $(89,97,101)$, it is likely that $\mathrm{Cl}$ will show no preference for anion over cation bonding on $\mathrm{GaSb}(110)$ or $\operatorname{InSb}(110)$ either.

Montgomery et al (90) investigated the room-temperature reaction of $\mathrm{Cl}_{2}$ with InP(110) by using LEED, AES, XPS, and ultraviolet photoelectron spectroscopy (UPS) and proposed that there are two stages of $\mathrm{Cl}_{2}$ adsorption: molecular adsorption followed by chemisorption. They also found that the reaction depletes the surface of $\mathrm{P}$ and forms a disordered chloride layer. Murrell et al $(18,19)$ studied the room-temperature reaction of $\mathrm{Cl}_{2}$ with $\operatorname{InP}(001)-4 \times 2$ by using LEED, AES, and TDS and found that the thermal desorption products are $\mathrm{InCl}_{3}, \mathrm{InCl}$, and $\mathrm{P}_{4}$. They also observed that the reaction occurs in two stages, a rapid one and a slower one, which they instead attributed to the chemisorption of a ML of $\mathrm{Cl}$ followed by the subsequent corrosion of the substrate. They further showed that the reaction is sensitive to the state of the starting surface, since increasing the In content of the surface enhances the reaction rate and leads to the formation of more $\mathrm{InCl}$.

\section{Bromine}

Only two fundamental studies have addressed the chemistry of bromine adsorption on a III-V semiconductor surface. Both considered the reaction of $\mathrm{Br}_{2}$ with GaAs(110). Using XPS and UPS, Cierocki et al (110) found that at room temperature $\mathrm{Br}_{2}$ dissociatively chemisorbs on $\mathrm{GaAs}(110)$, first forming a ML of surface $\mathrm{Br}$ and then, much more slowly, breaking substrate backbonds and incorporating $\mathrm{Br}$ into the substrate. Gu et al (121) investigated the monolayer and multilayer adsorption of $\mathrm{Br}_{2}$ on $\mathrm{GaAs}(110)$ in the temperature range $25-300 \mathrm{~K}$ by using core-level SXPS. The initial $\mathrm{Br}_{2}$ adsorption was found to be dissociative, with $\mathrm{Br}$ bound to both $\mathrm{Ga}$ and As sites. Gaseous $\mathrm{AsBr}_{3}$ and $\mathrm{GaBr}_{3}$ were formed by warming the substrate after multilayer $\mathrm{Br}_{2}$ adsorption. Both $\mathrm{Ga}-\mathrm{Br}$ and $\mathrm{As}-\mathrm{Br}$ species were observed after reaction at all temperatures studied, and the surface was found to etch stoichiometrically. 


\section{Iodine}

The earliest fundamental study of halogen reactions on a III-V semiconductor was published by Jacobi et al (145) in 1976, regarding the room-temperature adsorption of $I_{2}$ on As-terminated GaAs(111). In that investigation, it was found from an analysis of the volatile reaction products that iodine continuously etches GaAs(111) at room temperature, independent of the initial surface reconstruction. As a result of the reaction, $\mathrm{a} \mathrm{GaI}_{x}(x=0-3)$ overlayer forms, which can be thermally desorbed to generate an As-rich surface.

An interesting trend to note is that the adsorption of iodine, followed by annealing, appears to universally generate a group-V-terminated surface. An Sb-rich $\operatorname{InSb}(001)-c(4 \times 4)$ surface can be formed by adsorbing a ML of $\mathrm{I}_{2}$ on In-rich $\operatorname{InSb}(001)-4 \times 2$ at room temperature and annealing to $300^{\circ} \mathrm{C}(88$, 93). Adsorbing $\mathrm{I}_{2}$ on $\operatorname{InSb}(001)-\mathrm{c}(8 \times 2)$ or $-4 \times 1$ surfaces and annealing to $200^{\circ} \mathrm{C}$ generates a clean $1 \times 1$ surface, whereas annealing to $260^{\circ} \mathrm{C}$ forms an Sb-rich c $(4 \times 4)$ surface $(80)$. Heating iodinated Ga-rich GaAs(001)-4 × 1 and $\operatorname{GaAs}(001)-4 \times 6$, and As-rich GaAs(001)-c $(2 \times 8)$ surfaces results, in all cases, in a $\mathrm{c}(2 \times 8)$ reconstructed surface $(93)$. Also, In-rich $\operatorname{InAs}(001)-\mathrm{c}(8 \times$ $2)$ is transformed into As-rich InAs-c $(2 \times 8)$ by $\mathrm{I}_{2}$ exposure and annealing (93).

Similar to $\mathrm{Cl}_{2}$ reactions, there is a competition for $\mathrm{I}_{2}$ between etching and passivation, which depends on the surface structure and stoichiometry. Varekamp et al (93) determined, using SXPS, that $\mathrm{I}_{2}$ dissociatively chemisorbs, and by comparing results from various MBE-grown surfaces, they showed that iodine bonds to whichever atoms are exposed at the surface. Reaction at room temperature or below often halts as soon as approximately $1 \mathrm{ML}$ of iodine is adsorbed, as is the case for certain $\mathrm{GaAs}(001), \operatorname{InAs}(001)$, and $\mathrm{InSb}(001)$ reconstructions $(88,91,93)$. Yet, when exposed to excess $\mathrm{I}_{2}$, other surfaces etch, including As-terminated $\operatorname{GaAs}(111)$ (145), stoichiometric GaAs(110) (109), and In-rich $\operatorname{InSb}(001)-c(8 \times 2)(93)$.

\section{SUMMARY}

Surface science techniques have evolved to the point where they can now be successfully applied to real-life problems. Etching is a good example of such a problem. The methodology originally developed for studying the etching of silicon has been applied to the more complicated etching chemistry of III$\mathrm{V}$ semiconductors. Much of what has been learned is not only academically interesting, but is also of use to the manufacturers of microelectronic devices. In fact, this methodology, which is not limited to the study of semiconductor etching, can be applied to many other classes of materials and can thereby make an impact on many other technologies. 
Several trends are already apparent in the results of investigations of halogen reactions with III-V semiconductors. For example, molecular halogens dissociatively chemisorb, forming first monohalides and then di- and trihalides. Also, there is a competition between passivation and etching, which appears to be controlled, at least somewhat, by surface temperature, stoichiometry, and crystallinity. In the cases where passivation occurs, the halogens tend to form an ordered overlayer. On the other hand, when etching occurs, halogens seem to show no preference for bonding to group-III or group-V elements, but instead bond to whichever atoms are exposed at the surface.

Although abundant and detailed, the existing literature on the reaction of III-V semiconductor surfaces with halogens is by no means comprehensive. In its current state, it is insufficient to permit an accurate prediction of material properties resulting from a particular set of reaction conditions, and it does not provide complete guidance for the selection of processing conditions if surfaces of a particular morphology and composition are desired. What is needed most right now is more work to complement existing investigations. In particular, much remains to be learned about the lesser studied halogens ( $\mathrm{Br}$ and I), reactions with III-V substrates other than GaAs, and the effects of substrate doping on the reactions.

Any Annual Review chapter, as well as any article cited in an Annual Review chapter, may be purchased from the Annual Reviews Preprints and Reprints service.

1-800-347-8007; 415-259-5017; email: arpr@class.org

Visit the Annual Reviews home page at http://www.annurev.org.

\section{Literature Cited}

1. Ameen MS, Mayer TM. 1986. J. Appl. Phys. 59:967-68

2. Ameen MS, Mayer TM. 1988. J. Appl. Phys. 63:1152-57

3. Asakawa K, Sugata S. 1986. J. Vac. Sci. Technol. A 4:677-80

4. Balooch M, Olander DR, Siekhaus WJ. 1986. J. Vac. Sci. Technol. B 4:794-805

5. Barker RA, Mayer TM, Burton RH. 1982. Appl. Phys. Lett. 40:583-86

6. Chaplart J, Fay B, Linh NT. 1983. J. Vac. Sci. Technol. B 1:1050-52

7. Chinn JD, Fernandez A, Adesida I, Wolf ED. 1983. J. Vac. Sci. Technol. A 1:701-4

8. Davis RI, Wolf ED. 1990. J. Vac. Sci. Technol. B 8:1798-803

9. DeLouise LA. 1991. J. Appl. Phys. 70:1718-29

10. DeLouise LA. 1992. J. Appl. Phys. $72: 1608-15$
11. DeLouise LA. 1992. Vacuum 43:1083-85

12. Grande WJ, Johnson JE, Tang CL. 1990. J. Vac. Sci. Technol. B 8:1075-79

13. Itabashi N, Ono T, Ochiai I, Yamamoto S, Mochiji K. 1995. Jpn. J. Appl. Phys. 34:3631-36

14. Jackman RB, Tyrrell GC, Marshall D, French CL, Foord JS. 1991. Mater. Res. Soc. Symp. Proc. 223:215-20

15. Klinger RE, Greene JE. 1981. Appl. Phys. Lett. 38:620-22

16. McNevin SC, Becker GE. 1985. J. Appl. Phys. 58:4670-78

17. McNevin SC. 1986. J. Vac. Sci. Technol. A 4:695-96

18. Murrell AJ, Price RJ, Jackman RB, Foord JS. 1989. J. Phys.: Condens. Matter 1(Suppl. B): 179-80

19. Murrell AJ, Price RJ, Jackman RB, Foord JS. 1990. Surf. Sci. 227:197-207 
20. O'Brien WL, Paulsen-Boaz CM, Rhodin TN, Rathbun LC. 1988. J. Appl. Phys. 64:6523-29

21. Orrman-Rossiter KG, Armour DG. 1989. Nucl. Instrum. Meth. Phys. Res. B 42: 334-41

22. Orrman-Rossiter KG, Baht RS, Badheka R, Wadsworth M, Armour DG. 1989. Nucl. Instrum. Meth. Phys. Res. B 36:446-54

23. Pang SW, Lincoln GA, McClelland RW, DeGraff PD, Geis MW, Piancentini WJ. 1983. J. Vac. Sci. Technol. B 1:1334-37

24. Pang SW, Geis MW, Efremow NN, Lincoln GA. 1985. J. Vac. Sci. Technol. B 3:398-401

25. Scherer A, Craighead HG, Rourkes ML, Harbison JP. 1988. J. Vac. Sci. Technol. B 6:277-79

26. Skidmore JA, Coldren LA, Hu EL, Merz JL, Asakawa K. 1988. Appl. Phys. Lett. 53:2308-10

27. Sugimoto Y, Taneya M, Hidaka H, Akita K. 1990. J. Appl. Phys. 68:2392-99

28. Taneya M, Sugimoto Y, Akita K. 1989. J. Appl. Phys. 66:1375-81

29. Tyrrell GC, Marshall D, Beckman J, Jackman RB. 1991. J. Phys. Condens. Matter 3(Suppl. A):5179-86

30. Williston LR, Bello I, Lau WM. 1992. J. Vac. Sci. Technol. A 10:1365-70

31. Yuba Y, Ishida T, Gamo K, Namba S. 1988. J. Vac. Sci. Technol. B 6:253-56

32. Ibbotson DE, Flamm DL, Donnelly VM. 1983. J. Appl. Phys. 54:5974-81

33. Ibbotson D. 1988. Pure Appl. Chem. 60:703-8

34. Iida M, Kaibe HT, Okumura T. 1991. Jpn. J. Appl. Phys. 30:1581-84

35. Meyyappan M, McLane GF, Cole MW, Laraeu R, Namaroff M, et al. 1992. J. Vac. Sci. Technol. A 10:1147-51

36. Seaward KL, Moll NJ, Coleman DJ, Stickle WF. 1987. J. Appl. Phys. 61:235864

37. Taniguchi M, Murakawa T, Kajitani Y. 1992. Appl. Surf. Sci. 56-58:827-31

38. Freedman A, Stinespring CD. 1992. J. Phys. Chem. 96:2253-58

39. Ha JH, Ogryzlo EA. 1991. Plasma Chem. Plasma Proc. 11:311-21

40. Shimokawa F, Tanaka H, Uenishi Y, Sawada R. 1989. J. Appl. Phys. 66:261318

41. Yu ML, DeLouise LA. 1994. Surf. Sci. Rep. 19:285-380

42. Larsen PK, Feiner LF, Friedel P. 1987. Phys. Rev. B 35:757-64

43. Lishan DG, Hu EL. 1990. Appl. Phys. Lett. 56:1667-69
44. Lishan DG, Hu EL. 1990. J. Vac. Sci. Technol. B 8:1951-55

45. Sugata S, Asakawa K. 1987. J. Vac. Sci. Technol. B 5:894-901

46. Geis MW, Efremow NN, Lincoln GA. 1986. J. Vac. Sci. Technol. B 4:315-17

47. Ono T, Kashima H, Hiraoka S, Suzuki K. 1991. J. Vac. Sci. Technol. B 9:2798-801

48. Akita K, Taneya M, Sugimoto Y, Hidaka H, Katayama Y. 1989. J. Vac. Sci. Technol. B 7:1471-74

49. Clausen EM Jr, Harbison JP, Chang CC, Craighead HG, Florez LT. 1990. J. Vac. Sci. Technol. B 8:1830-35

50. Matsui S, Watanabe H. 1991. Appl. Phys. Lett. 59:2284-86

51. Meguro T, Ishii M, Kodama H, Hamagaki M, Hara T, et al. 1990. Jpn. J. Appl. Phys. 29:2216-19

52. Watanabe H, Matsui S. 1991. Jpn. J. Appl. Phys. 30:3190-94

53. Watanabe H, Matsui S. 1992. Jpn. J. Appl. Phys. 31:L810-12

54. Watanabe H, Matsui S. 1993. Jpn. J. Appl. Phys. 32:6158-62

55. Watanabe H, Matsui S. 1993. J. Vac. Sci. Technol. B 11:2288-93

56. Ashby CIH. 1984. Appl. Phys. Lett. 45: 892-94

57. Ashby CIH. 1985. Appl. Phys. Lett. 46: 752-54

58. Berman MR. 1991. Appl. Phys. A 53:44248

59. Brewer P, Halle S, Osgood RM Jr. 1984. Appl. Phys. Lett. 45:475-77

60. Brewer PD, McClure D, Osgood RM Jr. 1985. Appl. Phys. Lett. 47:310-12

61. Donnelly VM, Flamm DL, Tu CW, Ibbotson DE. 1982. J. Electrochem. Soc. 129:2533-37

62. Koren G, Hurst JE Jr. 1988. Appl. Phys. A 45:301-4

63. Qin QZ, Li YL, Jin ZK, Zhang ZJ, Yang YY, et al. 1988. Surf. Sci. 207:142-58

64. Qin Q-Z, Li Y-L, Jin Z-K, Liu X-N, Zheng Q-K. 1988. Chem. Phys. Lett. 149:128-33

65. Qin QZ, Li YL, Lu PH, Zhang ZJ, Jin ZK, Zheng QK. 1992. J. Vac. Sci. Technol. B 10:201-5

66. Ruberto MN, Willner AE, Podlesnik DV, Osgood RM Jr. 1989. Appl. Phys. Lett. 55:984-86

67. Shih MC, Freiler MB, Haase G, Scarmozzino R, Osgood RM Jr. 1992. Appl. Phys. Lett. 61:828-30

68. Takai M, Tsuchimoto J, Tokuda J, Nakai H, Gamo K, Namba S. 1988. Appl. Phys. A 45:305-12

69. Tejedor P, Briones F. 1994. J. Chem. Phys. 101:2600-5 
70. Winters HF, Coburn JW. 1992. Surf. Sci. Rep. 14:161-269

71. McFeely FR, Morar JF, Shinn ND, Landgren G, Himpsel FJ. 1984. Phys. Rev. B 30:764-70

72. Lo CW, Shuh DK, Chakarian V, Durbin TD, Varekamp PR, Yarmoff JA. 1993. Phys. Rev. B 47:15648-59

73. McFeely FR, Morar JF, Himpsel FJ. 1986. Surf. Sci. 165:277-87

74. Houle FA. 1986. J. Appl. Phys. 60:301827

75. Winters HF, Haarer D. 1987. Phys. Rev. B 36:6613-23

76. Himpsel FJ, Meyerson BS, McFeely FR, Morar JF, Taleb-Ibrahimi A, Yarmoff JA. 1990. In Enrico Fermi School on "Photoemission and Absorption Spectroscopy of Solids and Interfaces with Synchrotron Radiation”, ed M Campagna, R Rossi, pp. 203-36. Amsterdam: North-Holland

77. Dowben PA. 1987. CRC Crit. Rev. Solid State Mat. Sci. 13:191-210

78. Jones RG. 1988. Prog. Surf. Sci. 27:25160

79. Chadi DJ. 1978. Phys. Rev. Lett. 41:106265

80. Mowbray AP, Jones RG, McConville CF. 1991. J. Chem. Soc. Faraday Trans. 87:3259-65

81. Varekamp PR, Håkansson MC, Kanski J, Kowalski BJ, Olsson LÖ, et al. 1996. Surf. Sci. 352/354:387-90

82. Biegelsen DK, Bringans RD, Northrup JE, Swartz L-E. 1990. Phys. Rev. B 41:5701-6

83. Drathen P, Ranke W, Jacobi K. 1978. Surf. Sci. 77:L162-66

84. Biegelsen DK, Bringans RD, Northrup JE, Swartz L-E. 1990. Phys. Rev. Lett. 65:452-55

85. Margaritondo G, Rowe JE, Bertoni CM, Calandra C, Manghi F. 1981. Phys. Rev. B 23:509-12

86. Schnell RD, Rieger D, Bogen A, Wandelt K, Steinmann W. 1985. Solid State Commun. 53:205-8

87. Sullivan DJD, Flaum HC, Kummel AC. 1994. J. Chem. Phys. 101:1582-94

88. Jones RG, Singh NK, McConville CF. 1989. Surf. Sci. 208:L34-L41

89. Shuh DK, Lo CW, Yarmoff JA, Santoni A, Terminello LJ, McFeely FR. 1994. Surf. Sci. 303:89-100

90. Montgomery V, Williams RH, Varma RR. 1978. J. Phys. C 11:1989-2000

91. Mowbray AP, Jones RG. 1990. Vacuum 41:672-75

92. Mowbray A, Jones RG. 1991. Appl. Surf. Sci. 48-49:27-38
93. Varekamp PR, Håkansson MC, Kanski J, Shuh DK, Björkqvist M, et al. 1996. Phys. Rev. B. 54:2101-13

94. Varekamp PR, Håkansson MC, Kanski J, Björkqvist M, Göthelid M, et al. 1996. Phys. Rev. B 54:2114-20

95. Patrin JC, Weaver JH. 1993. Phys. Rev. B 48:17913-21

96. Patrin JC, Li YZ, Chander M, Weaver JH. 1993. Appl. Phys. Lett. 62:1277-79

97. Stepniak F, Rioux D, Weaver JH. 1994. Phys. Rev. B 50:1929-33

98. Margaritondo G, Rowe JE, Bertoni CM, Calandra C, Manghi F. 1979. In Physics of Semiconductors, ed. BLH Wilson, pp. 187-90. London: Inst. Phys.

99. Margaritondo G, Rowe JE, Bertoni CM, Calandra C, Manghi F. 1979. Phys. Rev. B 20:1538-45

100. Pengshou X, Texiu Z, Mongrong J. 1990. Phys. Scr. 41:996-97

101. Simpson WC, Tong WM, Weare CB, Shuh DK, Yarmoff JA. 1996. J. Chem. Phys. 104:320-25

102. Troost D, Koenders L, Fan L-Y, Mönch W. 1987. J. Vac. Sci. Technol. B 5:111924

103. Zhang K, Yeh L. 1981. J. Vac. Sci. Technol. 19:628-30

104. Ortega J, García-Vidal FJ, Pérez R, Rincón R, Flores F. 1992. Phys. Scr. T45:277-82

105. Rincón R, García-Vidal FJ, Flores F. 1995. Surf. Sci. 330:297-312

106. Simpson WC, Durbin TD, Varekamp PR, Yarmoff JA. 1995. J. Appl. Phys. 77:2751-58

107. Simpson WC, Varekamp PR, Shuh DK, Yarmoff JA. 1995. J. Vac. Sci. Technol. A 13:1709-13

108. Varekamp PR, Simpson WC, Shuh DK, Durbin TD, Chakarian V, Yarmoff JA. 1994. Phys. Rev. B 50:14267-76

109. Troost D, Koenders L, Mönch W. 1993. Appl. Surf. Sci. 66:619-24

110. Cierocki K, Troost D, Koenders L, Mönch W. 1992. Surf. Sci. 264:23-32

111. McLean AB, Terminello LJ, McFeely FR. 1989. Phys. Rev. B 40:11778-85

112. Smit K, Koenders L, Mönch W. 1989. J. Vac. Sci. Technol. B 7:888-93

113. Katnani AD, Sang HW Jr, Chiaradia P, Bauer RS. 1985. J. Vac. Sci. Technol. B 3:608-12

114. Van der Veen JF, Smit L, Larsen PK, Neave JH. 1983. Physica B \& C 117118:822-24

115. Schwartz GP, Gualtieri GJ, Kammlott GW, Schwartz B. 1979. J. Electrochem. Soc. 126:1737-49 
116. Simpson WC, Shuh DK, Yarmoff JA. 1996. J. Vac. Sci. Technol. In press

117. Corkill JL, Chelikowsky JR. 1994. Phys. Rev. B 50:11924-31

118. Corkill JL, Chelikowski JR. 1996. Phys. Rev. B. 53:12605-8

119. Khoo GS, Ong CK. 1994. Phys. Rev. B 50:10796-800

120. Simpson WC, Shuh DK, Hung WH, Håkansson MC, Kanski J, et al. J. Vac. Sci. Technol. A. 14:1815-21

121. Gu C, Chen Y, Ohno TR, Weaver JH. 1992. Phys. Rev. B 46:10197-200

122. Croyden WF, Parker EHC. 1981. Dielectric Films on Gallium Arsenide. New York: Gordon \& Breach

123. Alnot P, Olivier J, Fadley CS. 1989. J. Electron Spectrosc. Relat. Phenom. 49:159-73

124. Barrière AS, Desbat $B$, Guégan $H$, Lozano L, Séguelong T, et al. 1989. Thin Solid Films 170:259-71

125. Barrière AS, Couturier G, Guégan H, Séguelong T, Thabti A, et al. 1989. Appl. Surf. Sci. 41/42:383-89

126. Barrière AS, Desbat B, Grannec J, Guégan H, Séguelong T, Chazelas J. 1991. Thin Solid Films 196:65-73

127. Barrière AS, Couturier G, Gevers G, Guégan H, Séguelong T, et al. 1989. Thin Solid Films 173:243-52

128. Ricard H, Kim KH, Aizawa K, Ishiwara H. 1990. Jap. J. Appl. Phys. 29:L246062

129. Ricard H, Aizawa K, Ishiwara H. 1992. Appl. Surf. Sci. 56-58:888-93

130. Nienhaus H, Mönch W. 1996. Appl. Surf. Sci. In press

131. Hou H, Zhang Z, Chen S, Su C, Yan W,
Vernon M. 1989. App. Phys. Lett. 55:8013

132. Houle FA. 1991. In Chemical Perspectives of Microelectronic Materials II Symposium, ed LV Interrante, KF Jensen, LH Dubois, ME Gross, pp. 25-30. Pittsburgh: Mater. Res. Soc.

133. Su C, Dai Z-G, Lee GH, Vernon M. 1991. In Chemical Perspectives of Microelectronic Materials II Symposium, ed. LV Interrante, KF Jensen, LH Dubois, ME Gross, pp. 31-36. Pittsburgh: Mater. Res. Soc.

134. Su C, Hou H-Q, Lee GH, Dai Z-G, Vernon MF, Bent BE. 1993. J. Vac. Sci. Technol. B 11:1222-42

135. Troost D, Clemens HJ, Koenders L, Mönch W. 1993. Surf. Sci. 286:97-103

136. Pankratz J, Nienhaus H, Mönch W. 1994. Surf. Sci. 307-309:211-15

137. Ludviksson A, Xu M, Martin RM. 1992. Surf. Sci. 277:282-300

138. Mokler SM, Watson PR, Ungier L, Arthur JR. 1992. J. Vac. Sci. Technol. B 10:237177

139. DeLouise LA. 1991. J. Chem. Phys. 94:1528-42

140. DeLouise LA. 1991. Surf. Sci. Lett. 244:L87-95

141. DeLouise LA. 1991. J. Vac. Sci. Technol. A 9:1732-36

142. Flaum HC, Sullivan DJD, Kummel AC. 1994. J. Chem. Phys. 100:1634-48

143. Su C, Xi M, Dai Z-G, Vernon MF, Bent BE. 1993. Surf. Sci. 282:357-70

144. McNevin SC. 1986. J. Vac. Sci. Technol. B 4:1216-26

145. Jacobi K, Steinert G, Ranke W. 1976. Surf. Sci. 57:571-79 